\title{
Ocean acidification can mediate biodiversity shifts by changing biogenic habitat
}

Jennifer M. Sunday*1 ${ }^{1}$, Katharina E. Fabricius ${ }^{2}$, Kristy J. Kroeker ${ }^{3}$, Kathryn M. Anderson ${ }^{1}$, Norah E. Brown ${ }^{1}$, James P. Barry ${ }^{4}$, Sean D. Connell ${ }^{5}$, Sam Dupont ${ }^{6}$, Brian Gaylord ${ }^{7}$, Jason M. HallSpencer $^{8,9}$, Terrie Klinger ${ }^{10}$, Marco Milazzo ${ }^{11}$, Philip L. Munday ${ }^{12}$, Bayden D. Russell ${ }^{13}$, Eric Sanford $^{7}$, Vengatesen Thiyagarajan ${ }^{13}$, Megan L.H. Vaughan ${ }^{1}$, Steven Widdicombe ${ }^{14}$, and Christopher D. G. Harley ${ }^{1}$

${ }^{1}$ Department of Zoology and Biodiversity Research Centre, University of British Columbia, Vancouver, British Columbia, V6T174 Canada

${ }_{2}^{2}$ Australian Institute of Marine Science, PMB 3, Townsville, Queensland 4810, Australia

${ }^{3}$ Department of Ecology and Evolutionary Biology, University of California Santa Cruz, California 95064 USA

${ }^{4}$ Monterey Bay Aquarium Research Institute, Moss Landing, California 95039 USA

${ }^{5}$ Southern Seas Ecology Laboratories, School of Earth and Environmental Sciences, and Environment Institute, University of Adelaide, South Australia 5005, Australia

${ }^{6}$ Department of Biological and Environmental Sciences, University of Gothenburg, The Sven Lovén Centre for Marine Sciences, 45178 Fiskebäckskil, Sweden

${ }^{7}$ Bodega Marine Laboratory and Department of Evolution and Ecology, University of California at Davis, Bodega Bay, California 94923 USA

${ }^{8}$ Marine Biology and ecology research Centre, School of Marine Science and Engineering, Plymouth University, United Kingdom

${ }^{9}$ Shimoda Marine Research Centre, Tsukuba University, Japan

${ }^{10}$ School of Marine and Environmental Affairs, University of Washington, Seattle, Washington 98105 USA

${ }^{11}$ Dipartimento di Scienze della Terra e del Mare, University of Palermo, Palermo, Italy 
${ }^{12}$ ARC Centre of Excellence for Coral Reef Studies, School of Marine and Tropical Biology, James Cook University, Townsville, Queensland, Australia

${ }^{13}$ The Swire Institute of Marine Science and School of Biological Sciences, The University of Hong Kong, Hong Kong SAR

${ }^{14}$ Plymouth Marine Laboratory, Plymouth PL1 3DH, Devon, United Kingdom 
The effects of ocean acidification (OA) on the structure and complexity of biogenic habitat have been broadly overlooked. Here we explore how declining $\mathrm{pH}$ and carbonate saturation may affect the structural complexity of four major biogenic habitats in coastal marine systems, and make quantitative predictions of how these changes will affect the biodiversity of life that they support. Our analyses predict that indirect effects driven by OA on habitatforming organisms could lead to lower species diversity in coral reefs, mussel beds, and some macroalgal habitats, but increases in diversity in seagrass and other macroalgal habitats. Available in situ data support the prediction of decreased biodiversity in coral reefs, but not the prediction of biodiversity gains in seagrass beds. Thus, while acidification-driven habitat loss may magnify the direct negative effects of ocean acidification on biodiversity, we lack evidence of the predicted increase in biodiversity in systems where habitat-forming species could benefit from acidification. Overall, a combination of direct effects and communitymediated indirect effects will drive ecological change, and changes in the extent and structural complexity of biogenic habitat driven by ocean acidification will have especially important ecosystem effects.

Ocean acidification is projected to affect all areas of the ocean, with varying consequences for marine species, ecosystems, and their function ${ }^{1}$. Direct physiological effects of decreased $\mathrm{pH}$ or increased $\mathrm{CO}_{2}$ are readily detectable and typically include changes in survival, calcification, growth, development, reproduction, and abundance ${ }^{2}$. More difficult to project are the indirect effects of ocean acidification, which are important to understanding and anticipating the scope of ecosystem responses ${ }^{3}$.

Changes to biogenic habitat structure associated with ocean acidification represent a key alteration to benthic systems, with potentially large indirect effects on biodiversity. Relationships between the structural complexity of habitats and the diversity of organisms that they support are well 
documented for many habitat types (Fig. S1). Typically, species richness increases with the structural complexity, or often the local density, of the habitat (Fig. S1). Direct effects of declining $\mathrm{pH}$ on habitat-forming organisms are expected to vary depending on organism physiology and life history, but generalities are emerging from both laboratory and in situ studies. For example, growth and calcification tend to decrease among habitat-formers that rely on calcification for structure (e.g. oysters, mussels, and corals ${ }^{2}$ ), while the growth of non-calcifying autotrophs that rely on $\mathrm{CO}_{2}$ as a resource often increases ${ }^{4}$. However, scaling direct effects on growth up to ecosystem-level parameters such as habitat complexity or density is problematic ${ }^{5}$.

We use in situ observations of four habitat types across temporally or spatially varying $\mathrm{pH}$ gradients to indicate how complexity (when available) or local density of biogenic habitat is affected at the local ecosystem scale. We then use relationships between complexity and/or density of the habitat and local species richness, to project ecosystem-level changes in species richness, in order to illustrate possible impacts on biodiversity.

In a coral reef, habitat complexity declines along a naturally decreasing $\mathrm{pH}$ gradient maintained by a $\mathrm{CO}_{2}$ seep in Papua New Guinea (Fig. 1A). This trend occurs as a result of transitions to coral species with lower intrinsic complexity ${ }^{6}$. Projecting this outcome through known positive relationships between habitat complexity and species richness in tropical coral reefs (Fig. 1B) leads to the prediction that species richness will decline with expected changes in carbonate chemistry associated with ocean acidification (Fig. 1C).

In mussel beds of the U.S. Pacific Northwest, percent cover of large Mytilus mussels is projected to decline with declining $\mathrm{pH}$, to be replaced by species that lack the structural complexity of large Mytilus for supporting interstitial fauna (e.g. encrusting sponge, ephemeral and filamentous algae, barnacles; based on inter-annual transitions across a temporal gradient in $\mathrm{pH}$; Wootton et al. 2008, 
Fig. 1D). In the same region, species richness in mussel bed interstitial invertebrate communities has a positive but saturating relationship with percent cover of mussels (Fig. 1E), such that we predict no change in species richness over the range of habitat loss associated with the observed $\mathrm{pH}$ values (solid lines in Fig. 1, D-F). However, future declines in mean annual $\mathrm{pH}$ may lead to habitat loss beyond this range. We cautiously extrapolate the linear relationship between $\mathrm{pH}$ and mussel cover (dotted lines Fig. 1D) to demonstrate possible non-linear effects on mussel bed biodiversity in a future acidified ocean (dotted line, Fig. 1F). Thus, as mean $\mathrm{pH}$ declines beyond observed values, richness may decline linearly, or may switch to a precipitous decline. Emerging evidence suggests the effect of $\mathrm{pH}$ on mussel growth is dependent on food regime ${ }^{8,9}$, which can co-vary with expected changes in carbonate chemistry. This highlights the potential for alternate responses to those predicted.

For seagrass and fleshy erect macroalgae, we observe two divergent scenarios. In most cases, we observe increasing biomass of dominant structural macroalgae and seagrass with decreasing $\mathrm{pH}$ (Fig. 1, G and J). Positive relationships between density and species richness in both seagrass and macroalgae (Fig. 1, $\mathrm{H}$ and $\mathrm{K}$ ) leads to the prediction in these cases - all else being equal - of a potential local increase in species richness with ocean acidification (Fig. 1, I and L). However, there are some cases where the dominant photosynthetic habitat type was not found to increase, but instead decreased or showed no change in local density, while potentially competing photosynthetic species increased (Fig. 2, A-C). In these cases we expect a more complicated change in associated fauna and diversity, which we do not attempt to predict here.

The divergent responses observed in seagrass and fleshy macroalgae are consistent with a model of competitive replacement associated with enhanced $\mathrm{CO}_{2}$ concentrations, where the unequal effects of ocean acidification on species competing for space drives shifts in dominance. Conceptually, such changes may have predictable effects on structural complexity (Fig. 3). For example, macroalgal 
species with simpler body forms, faster growth and/or generational times may benefit more from additional $\mathrm{CO}_{2}$ compared to large canopy-forming $\operatorname{kelps}^{10}$, leading to an overall loss of structural complexity for associated biodiversity, despite increases in the performance of individual kelps (Fig. 3c; ref ${ }^{11}$ ). Recognizing such community context-dependency is critical for prediction of ecosystem-level responses, given its potential to accelerate ${ }^{12}$, buffer $^{13}$ or even reverse ${ }^{14}$ the effects of changing climate.

Data exist to test these projections in two of these habitat types. In a coral reef associated with the Papua New Guinea $\mathrm{CO}_{2}$ seep system, invertebrate taxonomic richness declines, as predicted, with decreasing $\mathrm{pH}$ and accompanying decreasing structural complexity (Fig. $1 \mathrm{C}$, ref $^{12}$ ). However, there was no change in fish species richness along the same gradient (Fig. 1C, ref ${ }^{15}$ ). The difference observed between invertebrates and fish in this system might be due to the small spatial scale of $\mathrm{CO}_{2}$ seeps relative to greater mobility of adult fish, or to a slower rate of diversity decline in fish compared to invertebrates along the gradients of reef complexity, as suggested by Fig. $1 \mathrm{~B}^{15}$. Next, in seagrass beds in the temperate Mediterranean $\mathrm{CO}_{2}$ seep system, no change in invertebrate species richness was observed in areas of reduced $\mathrm{pH}$ and increased seagrass shoot density ${ }^{16}$, contrary to the prediction of an increase in richness (Fig. 2C). Hence, either direct or indirect negative effects of ocean acidification on communities living in seagrass beds (e.g., decreases of calcifying epibionts despite increases in seagrass shoot density ${ }^{17}$ ), or the small spatial scale of the increased shoot density, override the expected positive effect of increased shoot density alone on species richness.

These test cases are few and early, and we caution that the space-for-time analogy required to interpret patterns around natural $\mathrm{CO}_{2}$ seeps is limited; other features of the habitat may vary in $\mathrm{CO}_{2}$ seeps such as seawater chemistry ${ }^{18}$ or substratum type, effects of ocean warming are not always included, and the small spatial scale and open nature of these habitats limits the potential for evolutionary responses ${ }^{19}$ and possibly of ecological responses of highly motile species. In addition, 
we have attempted to relate $\mathrm{pH}$ sensitivity observed in one location, with community diversity relationships at others, despite the expectation of context-dependency and interactions between multiple environmental drivers that influence ecological outcomes ${ }^{8}$. Furthermore, an additional imprint of ocean acidification on species diversity not explored here is its potential effect on habitat recovery after disturbance ${ }^{3}$. For example, because species diversity is theoretically unimodally related to the rate of recovery from disturbances, a delay in habitat recovery rates caused by ocean acidification may affect (increase or decrease) equilibrium diversity (see ref $^{3}$ ). Nevertheless, these case studies, focused on complexity and density of biogenic habitats, demonstrate that the effects of ocean acidification on habitats may critically interact with direct effects on resident species, and alter our predictions of future ocean change.

In other biodiverse biogenic habitats, we expect ocean acidification to affect structural complexity and biodiversity in a similar way. Structural complexity is nearly ubiquitously associated with increases in species richness, as demonstrated in seagrasses, macroalgae, sponges, ascidians, mussels, oysters, vermetid reefs, serpulid reefs, and coral reefs (Supplementary Figure 1). Effects of $\mathrm{CO}_{2}$ on structural complexity have been studied in only some of these habitats in situ (Supplementary Figure 2), however, changes in performance of habitat-forming species in laboratory and mesocosm studies ${ }^{10}$ suggest we may see changes at the population and community levels either through changes in dominant species or through changes in recovery rates after disturbances. Such changes stand to have far greater effects on marine biodiversity than individuallevel responses of each community member. This feature could accelerate direct negative effects on diversity, when OA decreases habitat complexity, but could retard or even reverse direct negative effects, when OA increases habitat complexity. While the call to focus on species interactions is a critical advance for ocean acidification research, the best research value will be gained by focusing on those species with relatively strong ecological interactions within their communities ${ }^{3,20}$, such as those that form the structural habitat supporting local diversity. 


\section{Methods}

\section{Effects of ocean acidification on biogenic habitat}

We collated studies of effects of $\mathrm{CO}_{2}$ on complexity or density of habitat-forming species, focusing on in situ studies across spatially varying $\mathrm{pH}$ gradients around $\mathrm{CO}_{2}$ seeps or temporally varying $\mathrm{pH}$ gradients in a region of changing $\mathrm{CO}_{2}$. Studies were included if percent cover, biomass density, or structural complexity were assessed as a function of $p \mathrm{CO}_{2}, \mathrm{pH}$, or aragonite saturation state. We noted studies of percent cover where a transition from the dominant habitat type to another within the same category (i.e., within calcifiers or non-calcifying autotrophs) was explicitly reported, e.g. changes from large fleshy macroalgae to turf algae, as these changes may (more likely) occur as a result of competition or differential recruitment. We found 3 cases and report these separately from the other data (Fig. 2).

\section{Biogenic habitat and associated community richness}

We gathered studies on associations between percent cover, biomass density, or structural complexity of habitat-forming species with richness or diversity of associated fauna. We excluded studies if the scale of structural complexity was smaller than the scale expected to be important to the associated biota (e.g. coralline frond density and meiofauna richness ${ }^{21}$ ).

\section{Case studies}

We chose case studies based on maximum reporting of relationships between habitat structure with $\mathrm{pH}$, and habitat structure with species richness metrics. We only included relationships where the metric of habitat structure (as percent cover or structural complexity) was directly comparable between measures of $\mathrm{pH}$ concentration and species richness. Because most studies reported relationships between habitat structure and $\mathrm{pH}$ (rather than $\mathrm{CO}_{2}$ or saturation state), we used this 
metric for the cases studies and excluded those where $\mathrm{pH}$ was not reported from the case studies (e.g. $\left.\operatorname{ref}^{22}\right)$.

\section{Test cases}

We searched for empirical relationships between community richness and $\mathrm{pH}$ within these four habitat groups, and found examples from a natural $\mathrm{CO}_{2}$ seep in a coral reef ecosystem (invertebrates ${ }^{12}$ fish $^{15}$ ) and in a seagrass ecosystem ${ }^{16}$. We present these examples next to predictions for visual comparison.

\section{Analysis}

We fit linear models to all relationships using maximum likelihood estimation, and included grouping variables from the original studies as random effects in these linear models. If a relationship visually appeared non-linear, we tested whether a non-linear model fit better (based on a lower Akaike Information Criterion) and if so, we present this relationship.

For the case studies, we present individual linear model fits, but we also pooled studies for each relationship and habitat type, and fit a linear mixed effects model to the full data, using location of study as a random effect on the intercept. For the effect of mussel habitats on community richness, we fit a non-linear saturating relationship to the individual and pooled studies, and generated estimates of error by bootstrapping 1000 model fits. We used these general (pooled studies) relationships to derive general predictions of habitat-mediated effects of $\mathrm{pH}$ on community richness. We used the model-predicted effects of $\mathrm{pH}$ on habitat structure as input variables for the modelpredicted effects of habitat structure on community richness. We projected estimates of error of these projected mean estimates by drawing, for each $\mathrm{pH}$ value and habitat, 1000 random estimates of complexity from a normal distribution with mean and standard deviation equal to the mean and standard error from the complexity model output. We used each of these complexity estimates to 
predict another 1000 estimates of richness, drawing from a normal distribution with mean and standard deviation equal to the mean and standard error of the richness model output, or for the mussel model (non-linear), we predicted richness for each complexity estimate using 1000 bootstrapped model fits. The $95 \%$ confidence interval for mean richness was calculated as the 0.025 and the 0.997 interquantile of the $1 \times 10^{6}$ mean richness estimates for each $\mathrm{pH}$ value. 


\section{References}

1. Gattuso, J.-P. et al. Contrasting futures for ocean and society from different anthropogenic CO2 emissions scenarios. Science (80-. ). 349, aac4722-1-aac4722-10 (2015).

2. Kroeker, K. J. et al. Impacts of ocean acidification on marine organisms: Quantifying sensitivities and interaction with warming. Glob. Chang. Biol. 19, 1884-1896 (2013).

3. Gaylord, B. et al. Ocean acidification through the lens of ecological theory. Ecology 96, 3-15 (2015).

4. Falkenberg, L. J., Russell, B. D. \& Connell, S. D. Contrasting resource limitations of marine primary producers: Implications for competitive interactions under enriched $\mathrm{CO} 2$ and nutrient regimes. Oecologia 172, 575-583 (2013).

5. Le Quesne, W. J. F. \& Pinnegar, J. K. The potential impacts of ocean acidification: scaling from physiology to fisheries. Fish Fish. 13, 333-344 (2012).

6. Fabricius, K. E. et al. Losers and winners in coral reefs acclimatized to elevated carbon dioxide concentrations. Nat. Clim. Chang. 1, 165-169 (2011).

7. Wootton, J. T., Pfister, C. A. \& Forester, J. D. Dynamic patterns and ecological impacts of declining ocean $\mathrm{pH}$ in a high-resolution multi-year dataset. Proc. Natl. Acad. Sci. U. S. A. 105, 18848-18853 (2008).

8. Kroeker, K. J. et al. Interacting environmental mosaics drive geographic variation in mussel performance and predation vulnerability. Ecol. Lett. 771-779 (2016). doi:10.1111/ele.12613

9. Thomsen, J., Casties, I., Pansch, C., Körtzinger, A. \& Melzner, F. Food availability outweighs ocean acidification effects in juvenile Mytilus edulis : laboratory and field experiments. Glob. Chang. Biol. 19, 1017-1027 (2013).

10. Connell, S. D., Kroeker, K. J., Fabricius, K. E., Kline, D. I. \& Russell, B. D. The other ocean acidification problem: $\mathrm{CO} 2$ as a resource among competitors for ecosystem dominance.

Proc. R. Soc. B Biol. Sci. 368, 1-9 (2013).

11. Nagelkerken, I., Russell, B. D., Gillanders, B. M. \& Connell, S. D. Ocean acidification alters 
fish populations indirectly through habitat modification. Nat. Clim. Chang. (2015). doi:10.1038/nclimate2757

12. Fabricius, K. E., De'ath, G., Noonan, S. \& Uthicke, S. Ecological effects of ocean acidification and habitat complexity on reef-associated macroinvertebrate communities. Proc. Biol. Sci. 281, 20132479 (2014).

13. Ghedini, G., Russell, B. D. \& Connell, S. D. Trophic compensation reinforces resistance: Herbivory absorbs the increasing effects of multiple disturbances. Ecol. Lett. 18, 182-187 (2015).

14. Harley, C. D. G. Climate change, keystone predation, and biodiversity loss. Science (80-. ). 334, 1124-1127 (2011).

15. Munday, P. L., Cheal, A. J., Dixson, D. L., Rummer, J. L. \& Fabricius, K. E. Behavioural impairment in reef fishes caused by ocean acidification at CO2 seeps. Nat. Clim. Chang. 1-6 (2014). doi:10.1038/NCLIMATE2195

16. Garrard, S. L. et al. Indirect effects may buffer negative responses of seagrass invertebrate communities to ocean acidification. J. Exp. Mar. Bio. Ecol. 461, 31-38 (2014).

17. Martin, S. et al. Effects of naturally acidified seawater on seagrass calcareous epibionts. Biol. Lett. 4, 689-692 (2008).

18. Vizzini, S. et al. Trace element bias in the use of $\mathrm{CO} 2$ vents as analogues for low $\mathrm{pH}$ environments: Implications for contamination levels in acidified oceans. Estuar. Coast. Shelf Sci. 134, 19-30 (2013).

19. Sunday, J. M. et al. Evolution in an acidifying ocean. Trends Ecol. Evol. 29, 117-125 (2014).

20. Harley, C. D. G., Pankey, M. S., Wares, J. P., Grosberg, R. K. \& Wonham, M. J. Color polymorphism and genetic structure in the sea star Pisaster ochraceus. Biol. Bull. 211, 24862 (2006).

21. Kelaher, B. P. Changes in habitat complexity negatively affect diverse gastropod assemblages in coralline algal turf. Oecologia 135, 431-41 (2003). 
22. Inoue, S., Kayanne, H., Yamamoto, S. \& Kurihara, H. Spatial community shift from hard to soft corals in acidified water. Nat. Clim. Chang. 3, 1-5 (2013).

23. Dustan, P., Doherty, O. \& Pardede, S. Digital Reef Rugosity Estimates Coral Reef Habitat Complexity. PLoS One 8, 1-10 (2013).

24. Graham, N. a J. et al. Dynamic fragility of oceanic coral reef ecosystems. Proc. Natl. Acad. Sci. U. S. A. 103, 8425-8429 (2006).

25. Gratwicke, B. \& Speight, M. R. The relationship between fish species richness, abundance and habitat complexity in a range of shallow tropical marine habitats. J. Fish Biol. 66, 650667 (2005).

26. Jones, G. P., McCormick, M. I., Srinivasan, M. \& Eagle, J. V. Coral decline threatens fish biodiversity in marine reserves. Proc. Natl. Acad. Sci. 101, 8251-8253 (2004).

27. Sadchatheeswaran, S., Branch, G. M. \& Robinson, T. B. Changes in habitat complexity resulting from sequential invasions of a rocky shore: implications for community structure. Biol. Invasions 17, 1799-1816 (2015).

28. Hall-Spencer, J. M. et al. Volcanic carbon dioxide vents show ecosystem effects of ocean acidification. Nature 454, 96-9 (2008).

29. Russell, B. D. et al. Future seagrass beds : Can increased productivity lead to increased carbon storage? Mar. Pollut. Bull. 73, 463-469 (2013).

30. Attrill, M., Strong, J. a \& Rowden, A. Are macroinvertebrate communities influenced by seagrass structural complexity? Ecography (Cop.). 23, 114-121 (2000).

31. Heck, K. L. \& Wetstone, G. S. Habitat complexity and invertebrate species richness and abundance in tropical seagrass meadows. 4, 135-142 (1977).

32. Stoner, A. W. \& Lewis, F. G. The influence of quantitative and qualitative aspects of habitat complexity in tropical sea-grass meadows. J. Exp. Mar. Bio. Ecol. 94, 19-40 (1985).

33. Enochs, I. C. et al. Shift from coral to macroalgae dominance on a volcanically acidified reef. Nat. Clim. Chang. 5, 1-9 (2015). 
34. Johnson, V. R., Russell, B. D., Fabricius, K. E., Brownlee, C. \& Hall-Spencer, J. M. Temperate and tropical brown macroalgae thrive, despite decalcification, along natural CO 2 gradients. Glob. Chang. Biol. 18, 2792-2803 (2012).

35. Linares, C. et al. Persistent natural acidification drives major distribution shifts in marine benthic ecosystems. Proc. R. Soc. B Biol. Sci. 282, 20150587 (2015).

36. Burnaford, J. L. Evaluating the relative roles of positive and negative interactions in communities: shade, herbivory and physiological stress in the rocky intertidal zone. (2002).

37. Lilley, S. A. \& Schiel, D. R. Community effects following the deletion of a habitat-forming alga from rocky marine shores. Oecologia 148, 672-681 (2006).

38. Torres, A. C., Veiga, P., Rubal, M. \& Sousa-Pinto, I. The role of annual macroalgal morphology in driving its epifaunal assemblages. J. Exp. Mar. Bio. Ecol. 464, 96-106 (2015).

39. Watt, C. A. \& Scrosati, R. A. Bioengineer effects on understory species richness, diversity, and composition change along an environmental stress gradient: Experimental and mensurative evidence. Estuar. Coast. Shelf Sci. 123, 10-18 (2013).

40. Willis, T. J. \& Anderson, M. J. Structure of cryptic reef fish assemblages: Relationships with habitat characteristics and predator density. Mar. Ecol. Prog. Ser. 257, 209-221 (2003).

41. Kroeker, K. J., Gambi, M. C. \& Micheli, F. Community dynamics and ecosystem simplification in a high-CO2 ocean. Proc. Natl. Acad. Sci. U. S. A. 110, 12721-6 (2013).

Acknowledgements: This article emerged from a working group funded by the Peter Wall Institute for Advanced Studies. We are grateful to R. Bechmann for helpful discussions, and thank the U.S. National Science Foundation, the National Science and Engineering Research Council of Canada, and several of our institutions for research support. 
Author Contributions: All authors conceptualized and designed the paper; JS, KF, KK, KA, $\mathrm{NB}, \mathrm{JH}-\mathrm{S}, \mathrm{MM}$, and $\mathrm{CH}$ assembled the data; JS analyzed the data, produced figures and drafted the paper; all authors contributed discussion, writing, and interpretation.

Competing Financial Interests statement: We report no competing financial interests.

\section{Figures}


$\mathrm{pH}$ effects on habitat

(single-habitat responses only)
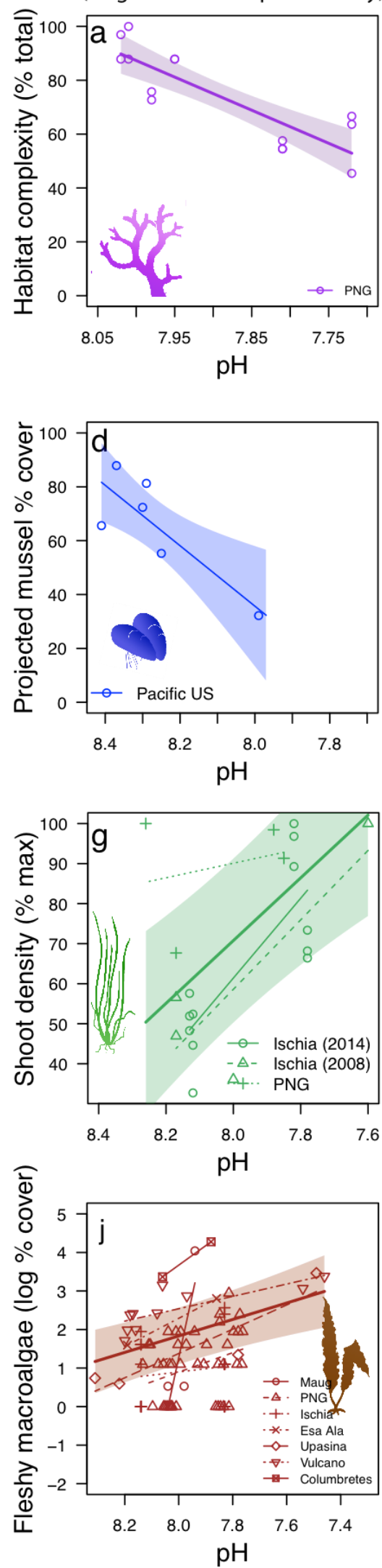

Habitat effects on diversity

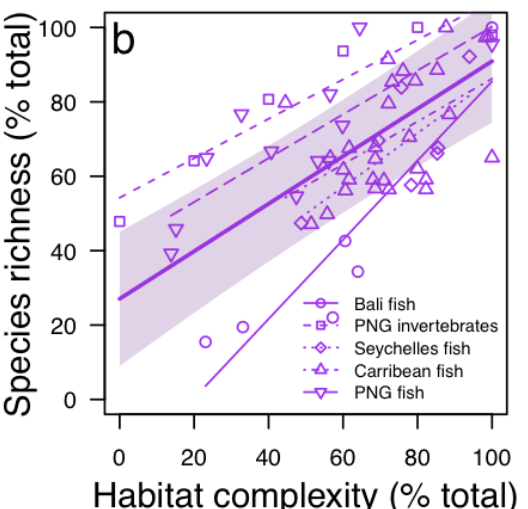

Habitat complexity (\% total)
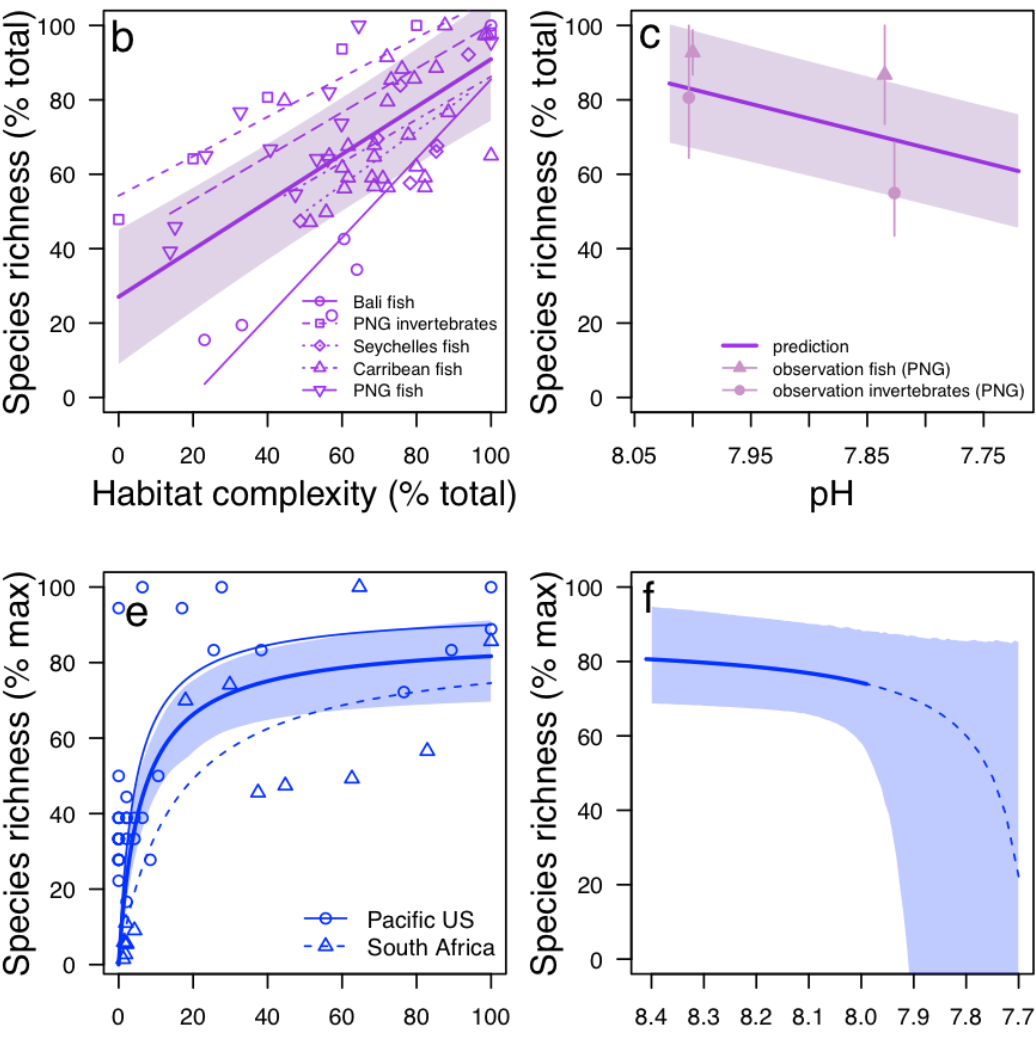

Mussel cover/complexity (\% max)

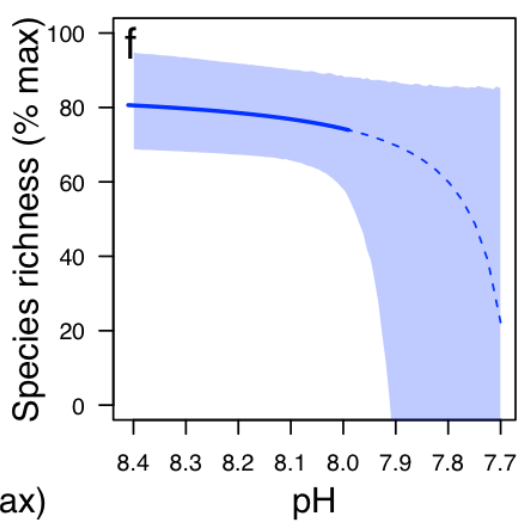

$\mathrm{pH}$

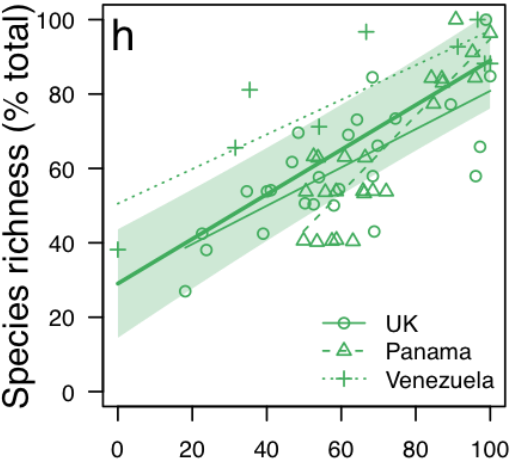

Biomass density (\% max)
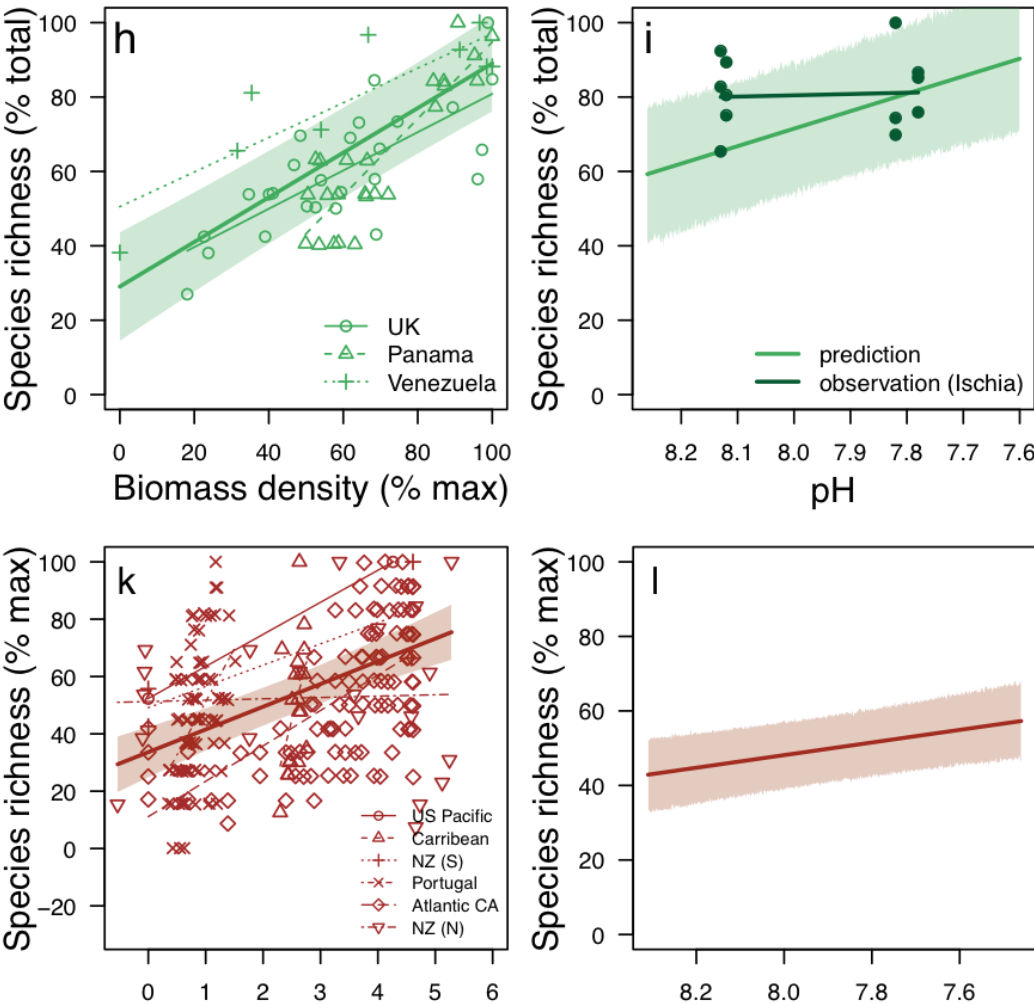

Fleshy macroalgae (log \% cover)

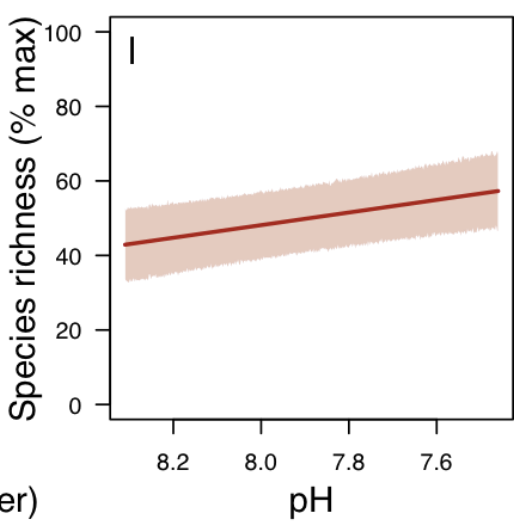


Figure 1. Observed and predicted relationships between $\mathrm{pH}$, habitat structure, and community richness in four focal habitats, based on published data. Changes in habitat complexity/density along spatial gradients from high to low $\mathrm{pH}$ regimes (a: coral reefs, $\mathbf{d}$ : mussel beds, $\mathbf{g}$ : seagrass meadows, $\mathbf{j}$ : macroalgae), and effects of habitat complexity/density on species richness of associated taxa (b,e,h,k), showing the fitted line from the linear models within studies (thin lines), and across studies (thick lines with shaded regions showing 95\% confidence interval). c,f,i,l Implied effects of $\mathrm{pH}$ on species richness projected from linear models (lines with shaded regions showing 95\% confidence interval, see methods), and observed relationships between species richness and $\mathrm{pH}$ (points in $\mathrm{c}$ and $\mathrm{i}$, with standard errors in $\mathrm{c}$ ). Dotted lines in $\mathrm{d}$ and $\mathrm{f}$ represent extrapolation of relationship beyond observed $\mathrm{pH}$ values within the time-series of ref $^{7}$. Data sources by panel: $\mathrm{a}^{12}$, $\mathrm{b}^{12,23-26}, \mathrm{c}^{12,15}, \mathrm{~d}^{7}, \mathrm{e}^{14,27}, \mathrm{~g}^{16,28,29}, \mathrm{~h}^{30-32}, \mathrm{i}^{16}, \mathrm{j}^{6,28,33-35}, \mathrm{k}^{25,36-40}$. 

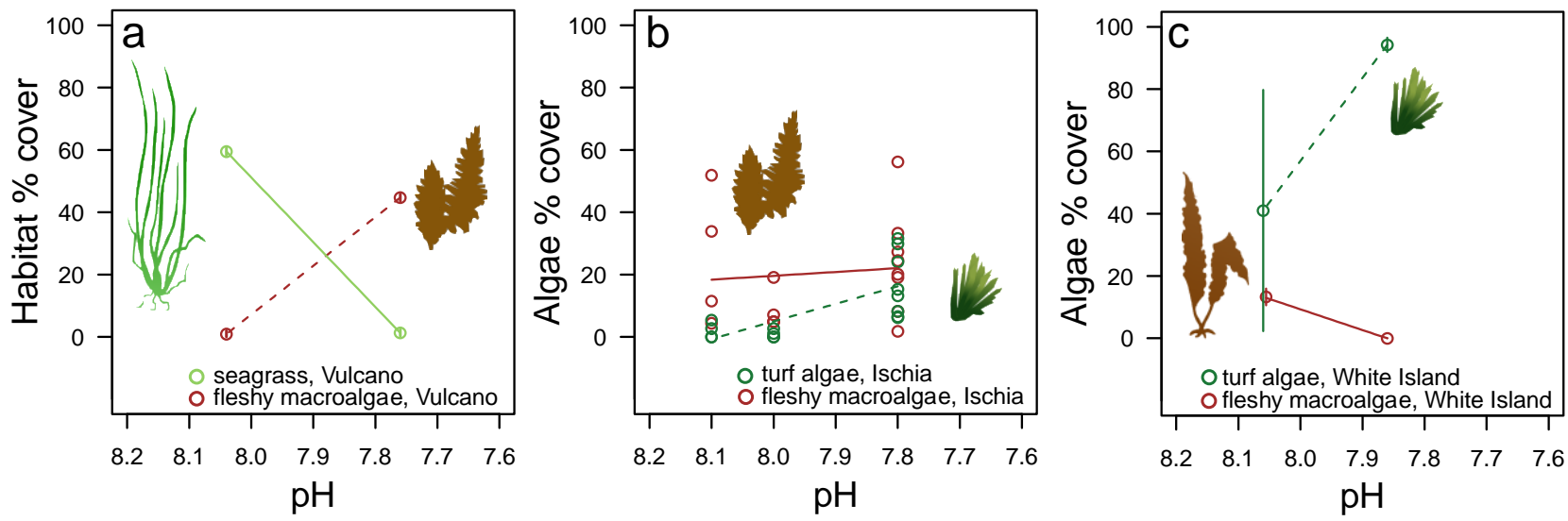

Figure 2. Changes in habitat density along spatial gradients from high to low $\mathrm{pH}$ regimes, showing cases where alternate habitat types were reported. Solid lines show responses in dominant structureforming species, dotted lines show responses in less-dominant or less-structural species. Data sources: $\mathrm{a}^{11}, \mathrm{~b}^{41}, \mathrm{c}^{11}$. 


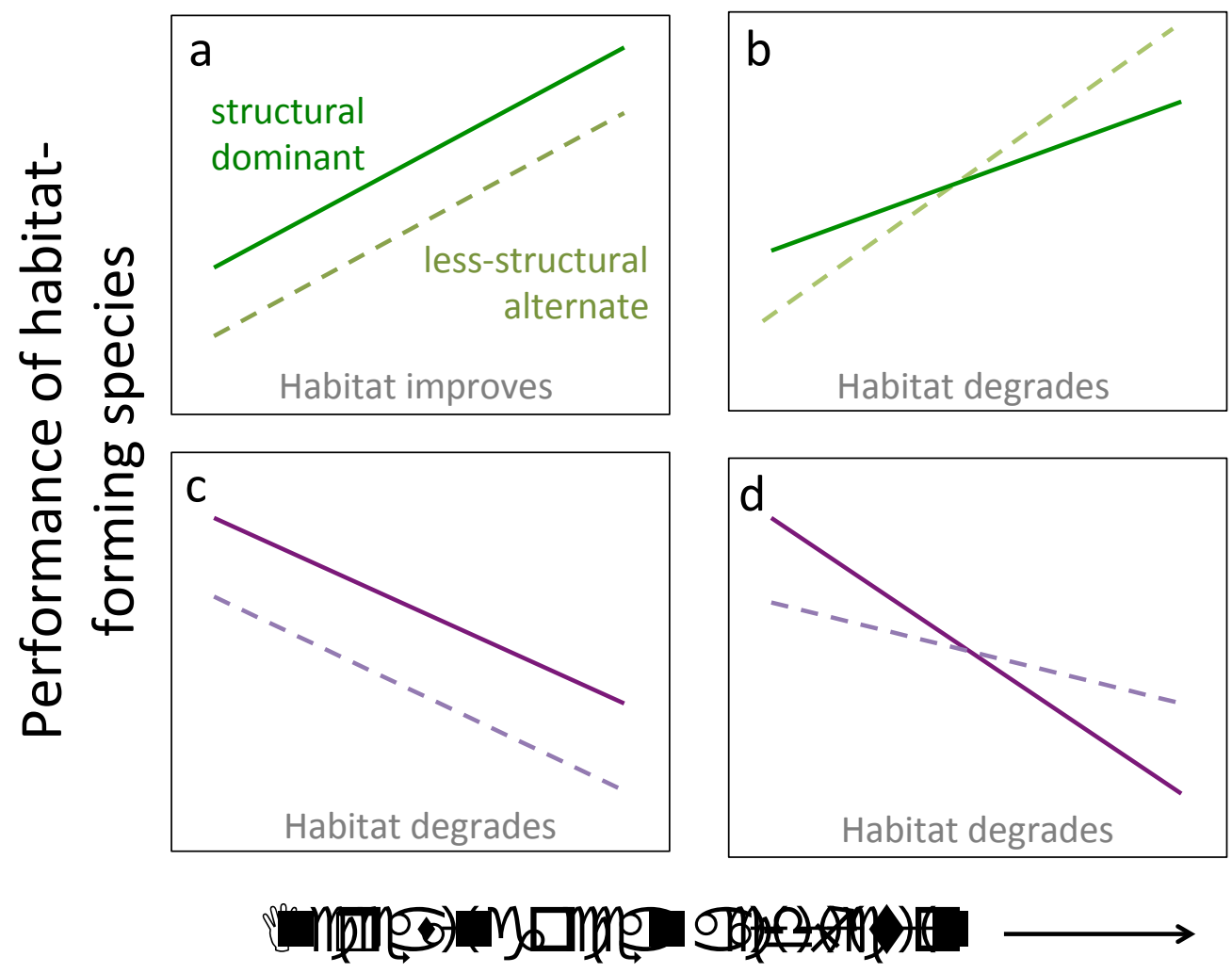

Figure 3. Conceptual model showing potential effects of ocean acidification on relative performance on competing habitat-forming organisms. Effects of ocean acidification on noncalcifying photosynthesizers are expected to be generally positive (A-B), but smaller and more ephemeral competitors (dashed line) may have faster rates of performance increases (solid line, B). At the local ecosystem level, the scenario in (B) may lead to a competitive shift in dominance towards species with lower intrinsic complexity, and thus a decline in habitat quality for associated taxa despite increasing performance in both groups of habitat forming species. Effects on calcifying habitat formers are expected to be negative (C-D), but less-structural forms (dashed lines) may be less negatively impacted compared to those forming greater structural complexity (solid lines). As a result, total habitat density may be less impaired than expected through species replacement, but there may be a decline in habitat quality for associated taxa due to replacement by species with lower structural complexity (scenario predicted from D). 